\title{
EchoGéo
}

19 | 2012

Du littoral à la haute mer : quelles recherches récentes en géographie?

\section{Entretien avec Michael Duarte}

Maria Gravari-Barbas et Sébastien Jacquot

\section{(2) OpenEdition \\ Journals}

Édition électronique

URL : https://journals.openedition.org/echogeo/13004

DOI : 10.4000/echogeo.13004

ISSN : 1963-1197

Éditeur

Pôle de recherche pour l'organisation et la diffusion de l'information géographique (CNRS UMR 8586)

Référence électronique

Maria Gravari-Barbas et Sébastien Jacquot, «Entretien avec Michael Duarte », EchoGéo [En ligne], 19 2012, mis en ligne le 10 février 2012, consulté le 11 août 2021. URL : http://journals.openedition.org/ echogeo/13004; DOI : https://doi.org/10.4000/echogeo.13004

Ce document a été généré automatiquement le 11 août 2021.

EchoGéo est mis à disposition selon les termes de la licence Creative Commons Attribution - Pas d'Utilisation Commerciale - Pas de Modification 4.0 International (CC BY-NC-ND) 


\title{
Entretien avec Michael Duarte
}

\author{
Maria Gravari-Barbas et Sébastien Jacquot
}

1 Michel Duarte est Chargé de développement depuis 2008 au Comité départemental de tourisme de Seine-Saint-Denis

2 - Maria Gravari-Barbas (MGB), Sébastien Jacquot (SJ). Vous travaillez depuis 2008 en tant que Chargé de mission au Comité département du tourisme de Seine-Saint-Denis. Quelle est la relation que vous établissez avec votre parcours universitaire en géographie?

3 - Michel Duarte (MD).Après avoir obtenu un baccalauréat ES en 2003, j'ai opté pour une formation en géographie à l'université Paris 7. Ma licence de géographie mention géographie humaine en poche, j'ai choisi de m'orienter vers un cursus plus professionnel et de découvrir l'univers du tourisme, secteur que je pensais très proche de la géographie. J'ai donc intégré le Master Développement et aménagement touristique des territoires. Actuellement en poste au comité départemental du tourisme de la Seine-Saint-Denis, je suis en charge du développement touristique et de la mise en réseau des acteurs en lien avec ce secteur d'activité. Ce travail est par définition territorialisé et implique une connaissance approfondie des ressources locales et de leur spatialisation

4 La formation en géographie m'a permis d'avoir cette compréhension des territoires et m'a donné un socle pour construire ensuite les actions et les projets touristiques. En effet, il est indispensable de bien assimiler les concepts clés de la géographie (la notion de déplacement, les spécificités démographiques, politiques, physiques d'un territoire...) pour pouvoir développer une activité touristique pérenne.

5 - MGB, SJ. En quoi votre formation de géographe vous a-t-elle permis de vous approprier les différents dossiers sur lesquels vous travaillez actuellement? De quelle manière la pensée géographique structure-t-elle votre approche professionnelle?

6 - MD. La pensée géographique permet de bien discerner les spécificités d'un territoire. Avant le développement de projets touristiques, il est nécessaire de bien comprendre le fonctionnement des lieux: comment s'est structuré le territoire? Quel est l'héritage 
laissé par l'histoire? Quelles sont les dynamiques actuelles ? Où se concentrent les flux de populations?

7 Dans le cas de la Seine-Saint-Denis, il est indispensable de comprendre l'héritage politique et socio-démographique et sa relation de proximité avec la première destination touristique, Paris, pour pouvoir y développer des projets à vocation touristique. Ne pas prendre en compte ces considérations serait, à mon sens, une erreur. Or, elles sont profondément géographiques.

8 De manière plus précise, je travaille depuis 2008 sur la mise en valeur touristique $d u$ canal de l'Ourcq qui relie Paris et la Seine-Saint-Denis. Il a fallu avant toute chose étudier l'histoire du lieu, comprendre l'origine de l'abandon du site par les institutions publiques et les habitants et déterminer les dynamiques actuelles (le nouvel intérêt des villes pour le canal, les futurs projets d'aménagements...).

9 Pour appréhender ces nombreuses questions, il a fallu utiliser trois outils indispensables pour tout géographe : assimiler l'approche historique du lieu, étudier les nombreuses cartes à ma disposition (cartes démographiques, urbanistiques, déplacements des cyclistes...) et observer le fonctionnement du lieu sur le terrain.

L'approche territoriale est primordiale pour le CDT 93. En effet, penser le tourisme en Seine-Saint-Denis revient à développer des projets en lien avec les caractéristiques des lieux et capables de s'adapter à la fois aux habitants et aux touristes. 